\title{
Magnetic Properties of Some Divalent Transition Metal Cupferron Complexes
}

\author{
A. H. Авou El Ela and H. H. Afifi \\ Physics Department, National Research Centre Cairo, Egypt \\ (Z. Naturforsch. 29 b, 524-526 [1974]; received April 30, 1974) \\ Magnetic moments, Cupferron complexes, Copper
}

\begin{abstract}
The magnetic susceptibilities and magnetic moments of the ammonium salt of cupferron and manganese, cobalt, nickel and copper divalent complexes are investigated. The ammonium salt of cupferron is diamagnetic while the divalent transition metal cupferron complexes exhibit paramagnetic behaviour. For manganese, cobalt and nickel cupferrates the magnetic moment is smaller than the spin-only value, which reflects the effect of the orbital angular momentum and electron delocalization. For copper cupferrate the magnetic moment is nearly equal to the spin-only value.
\end{abstract}

The magnetic properties of transition metal complexes are of interest since specific information about the electronic structure of these complexes could be obtained from magnetic measurements.

Cupferron is a well known chelating agent. YoSHIMURA $^{1}$, studied the IR and UV spectra of cupferron and neocupferron. Recently, detailed analysis of the IR and UV spectra of cupferron and some divalent transition cupferron complexes were reported $^{2-4}$. The electronic structures of these complexes were studied from the absorption spectroscopy point of view. A tetrahedral crystal field was suggested for the divalent transition metal complexes investigated.

The present contribution is aimed to investigate the magnetic properties of the ammonium salt of cupferron and some divalent transition cupferrate complexes. The results obtained are interpreted on the basis of ligand field theory.

\section{Experimental}

All chemicals used were A. R. grade, B. D. H. label. The ammonium salt of cupferron was obtained from Hungary "Reanal, finomvegyszergyar, Budapest." The different cupferrate complexes were prepared by the method described earlier ${ }^{2}$. Elemental chemical analysis for the metal complexes prepared gave a chemical composition of

Requests for reprints should be sent to Dr. A. H. Aвоu El Ela, Semiconductor Research Lab., National Research Centre El Dokki, El Tahrir Street, Cairo, U.A.R.
$\mathrm{ML}_{2}$, where $\mathrm{M}$ stands for the metal ( $\mathrm{Mn}, \mathrm{Co}, \mathrm{Ni}$ and copper) and $\mathrm{L}$ for the ligand $\left(\mathrm{C}_{6} \mathrm{H}_{5} \mathrm{O}_{2} \mathrm{~N}_{2}\right)$.

The Gouy method has been used for the compounds investigated in the powder form. Measurements were carried out in quartz ampoules, each ampoule was suspended so that the lower end of the sample was in the center of a homogenous magnetic field. Moreover, the ampoule was symmetrical with respect to the polepieces of the magnet and consequently, the interactions of the upper and lower half of the ampoule with the magnetic field were mutually compensated. The mean susceptibility was measured for the compounds. Corrections for the porosity of the powder inside the specimen tube was applied. Different magnetic field intensities were used and the diamagnetic correction for the ligand was considered. Pure distilled water was used as a standard. Its susceptibility at $t\left[{ }^{\circ} \mathrm{C}\right]$ is given dy

$$
\begin{aligned}
& \chi_{\mathrm{w}}=-[0.72145+0.000108(t-20)] 10^{-6} \text { s.g.s.e. } \\
& \text { m.u. }
\end{aligned}
$$

\section{Results and Discussion}

The mean values of the magnetic moments of the different complexes is shown in Table I. The results are compared with the spin-only magnetic moment calculated for the ions considered ${ }^{5}$. All the transition metal cupferron complexes show paramagnetic behaviour. The magnetic moment, determined experimentally, is smaller than the spin-only magnetic moment $\mu^{\mathrm{s} \cdot o}=\mathrm{S}(\mathrm{S}+1)^{1 / 2}$, only in the case of copper cupferrate the magnetic moment obtained (1.76 B.M) is nearly equal to the spin-only value (1.73 B.M.).

FigGis ${ }^{5}$ shows, that there is likely to be a loss of 
Table I. The magnetic moments of cupferron and some divalent transition metal cupferron complexes.

\begin{tabular}{|c|c|c|c|c|c|}
\hline Compound & Ion & Ground term & $\begin{array}{l}\text { No. of unpaired } \\
\text { d electrons }\end{array}$ & $\begin{array}{l}\text { Magnetic } \\
\text { moment meas- } \\
\text { ured [B.M.] }\end{array}$ & $\begin{array}{l}\text { Magnetic } \\
\text { moment spin- } \\
\text { only calculated } \\
\text { [B.M.] }\end{array}$ \\
\hline Cupferron & & & & -0.382 & \\
\hline Mn (Cup.). & $\mathrm{Mn}^{2+}$ & ${ }^{6} \mathrm{~A}_{1}(\mathrm{~S})$ & 5 & 4.92 & 5.92 \\
\hline Co (Cup.) $)_{2}$ & $\mathrm{Co}^{2+}$ & ${ }^{4} \mathrm{~A}_{2}(\mathrm{~F})$ & 3 & 3.4 & 3.87 \\
\hline $\mathrm{Ni}$ (Cup. $)_{2}$ & $\mathrm{Ni}^{2+}$ & ${ }^{3} \mathrm{~T}_{1}(\mathrm{~F})$ & 2 & 2.32 & 2.83 \\
\hline $\mathrm{Cu}$ (Cup. $)_{2}$ & $\mathrm{Cu}^{2+}$ & ${ }^{2} \mathrm{~T}_{2}(\mathrm{D})$ & 1 & 1.76 & 1.73 \\
\hline
\end{tabular}

orbital angular momentum upon the incorporation of the free ion into a complex. For complexes with $\mathrm{A}$ and $\mathrm{E}$ ground terms the orbital angular momentum is quenched, while it may exist for complexes with $\mathrm{T}_{1}$ and $\mathrm{T}_{2}$ ground terms. Inspite of these facts the magnetic moments of complexes with $\mathrm{A}$ and $\mathrm{E}$ ground terms usually differ appreciably from the spin-only value to which they are expected to conform in the absence of orbital angular momentum in the ground term. The reason for departure from the spin-only value lies partly in the existence of the second order Zeeman effect between the ground and the higher ligand field terms. However, it lies mainly in the fact that, in the presence of spin-orbit coupling, the quenching effect of the ligand field cannot be complete. Therefore, the magnetic susceptibility of complexes possessing $\mathrm{A}$ and $\mathrm{E}$ ground terms should be a Curie law dependence plus a small constant term (temperature independent paramagnetism T.I.P.).

For complexes with ${ }^{6} \mathrm{~A}_{1}$ ground term $\left(\mathrm{Mn}^{2+}\right)$ the magnetic moment should equal to the spin-only value (according to ligand field theory) while the T.I.P is zero. The value measured for the magnetic moment of $\mathrm{Mn}^{2+}$ in manganese cupferrate (4.92 B.M.) is smaller than the calculated value for spinonly moment which contradicts the theoretical conclusions. The difference could be attributed to the effect of residual orbital angular momentum or to the occurence of a distortion in the crystal field.

For $\mathrm{Co}^{2+}$ complexes with ${ }^{4} \mathrm{~A}_{2}$ ground term the magnetic moment from the first order Zeeman effect and the T.I.P susceptibility are given $b y^{5,6}$

$$
\begin{gathered}
\mu_{\mathrm{eff}}=\mu_{\mathrm{eff}}^{\text {s.o. }}\left(1-\frac{4 k^{2} \lambda_{\mathrm{o}}}{|10 \mathrm{Dq}|}\right), \\
\chi_{\text {T.I.P }}=\frac{8 k^{2} \mathrm{~N} \beta}{|10 \mathrm{Dq}|}
\end{gathered}
$$

where $\lambda_{0}= \pm \frac{\zeta}{2 \mathrm{~S}}$ is the spin-orbit coupling parameter, $\zeta$ is the single electron spin-orbit coupling constant, $10 \mathrm{Dq}$ is the separation between the e and $t_{2}$ orbitals, $k$ is a factor which accounts for the reduction of the orbital angular momentum of a metal ion consequent upon the delocalization of electrons out of the $t_{2}$ orbitals of the ion onto the ligand atoms to form the molecular orbitals of the complex, $\mathrm{N}$ and $\beta$ are Avogadro's number and Bohr Magneton.

The difference between the value obtained for the magnetic moment of $\mathrm{Co}^{2+}$ in cobalt cupferrate (3.4 B.M.) and the spin-only value $\left(\mu^{\mathrm{s} .0} .=3.87\right)$ is evidence of a small degree of electron delocalization. Optical absorption measurements ${ }^{3,4}$ shows that the transition ${ }^{4} \mathrm{~A}_{2}(\mathrm{~F}) \rightarrow{ }^{4} \mathrm{~T}_{1}(\mathrm{P})$ in cobalt cupferrate occurs around $16000 \mathrm{~cm}^{-1}$, therefore applying TANABE-SUGANO diagrams ${ }^{7}$ a value for $|10 \mathrm{Dq}|$ $\sim 3530 \mathrm{~cm}^{-1}$ is obtained. Using the above mentioned relations, the value obtained for the "orbital reduction" or "delocalization" factor is $k \sim 0.75$. The LANDÉ splitting factor could be also obtained from the relation

$$
\mathrm{g}=2\left(1-\frac{4 k^{2} \lambda_{0}}{|10 \mathrm{Dq}|}\right) \simeq 2.218
$$

Therefore, the reduction observed in the room temperature magnetic moment does not arise principally from an increase in the splitting of the orbital quartet even when appreciable distortion is to be expected, but the main factor seems to be a decrease in the value of the electron delocalization parameter $k$.

The difference between the measured value of the magnetic moment for $\mathrm{Ni}^{2+}$ in nickel cupferrate (2.32 B.M.) and the spin-only value (2.83 B.M.) could be attributed to a small electron delocalization effect. From optical absorption data ${ }^{3,4}$ three 
absorption bands were observed at $625 \mathrm{~nm}, 641 \mathrm{~nm}$ and $700 \mathrm{~nm}$ with the center of gravity $\sim 15300 \mathrm{~cm}^{-1}$. These bands represents a single transition, ${ }^{3} \mathrm{~T}_{1}(\mathrm{~F}) \rightarrow$ ${ }^{3} \mathrm{~T}_{1}(\mathrm{P})$, split by either spin-coupling mechanism or a low symmetry ligand field. Using TANABESUGANO diagrams a value of $|10 \mathrm{Dq}| \sim 2200 \mathrm{~cm}^{-1}$ is obtained. Approximate calculations shows, that the ligand field parameter $\mathrm{A}$ is about 1.35, therefore, the crystal field may be considered to be a medium one (for weak field $\mathrm{A}=1.5$ and for strong field $\mathrm{A}=1$ ).

Measurements of the magnetic moment of $\mathrm{Cu}^{2+}$ in copper cupferrate give a value $\mu=1.76$ B.M., which is nearly equal to the spin-only value $(1.73$ B.M.). This result shows a strong reduction of orbital angular momentum. The magnetic susceptibility could be described by a model in which the system is an ensemble of $\mathrm{S}=1 / 2$ units each with a

1 T. Yoshimura, C. Miyake, and S. Imoto, Bull. chem. Soc. Jap. 45, 5, 1424 [1972].

${ }^{2}$ A. H. Abou El Ela, F. M. Abdel Kerim, H. H. Afrfi, and H. F. Aly, Z. Naturforsch. 28b, 610 [1973].

3 A. H. Abou El Ela and H. H. Afifi, Z. Naturforsch. 29a, [1974].

${ }^{4}$ A. H. Abou El Ela and H. H. Afifi, Z. Naturforsch. 29a, [1974].

${ }^{5}$ B. N. FigGis, Introduction to Ligand Fields, Interscience Publishers, New York 1966. ground-state singlet and excited triplet obeying Boltzmann statistics

$$
\chi=\frac{2 \mathrm{Ng}^{2} \beta^{2}}{3 k \mathrm{~T}} \cdot \frac{1}{1+\frac{1}{3} \frac{\Delta \varepsilon}{\mathrm{e}^{\mathrm{KT}}}}+\text { small T.I.P }
$$

where $\Delta \varepsilon$ is the singlet-triplet separation. Approximate calculations show, that the value of the activation energy $\Delta \varepsilon$ for $\mathrm{Cu}^{2+}$ in copper cupferrate is $\sim 0.04 \mathrm{eV}$. The $\mathrm{g}$ factor could be calculated from the experimental data in the Curie-Wiess range using the spin-only formula ${ }^{9}$

$$
\chi=\frac{\mathrm{Ng}^{2} \beta^{2}}{3 k \cdot \mathrm{T}} \mathrm{S}(\mathrm{S}+1)(\text { with } \mathrm{S}=1 / 2
$$

a value of $\mathrm{g}=1.932$ was obtained.

The authors wish to thank Dr. H. F. Aly for previous discussion on the preparation of the complexes.

${ }^{6}$ B. N. Figgis, M. Gerbach, and R. Mason, Proc. Roy. Soc. A 279, 210 [1964].

7 Y. TAnabe and S. Sugano, J. chem. Soc. Jap. 9, 753 [1954].

8 G. J. Maas, B. C. Gerstein, and R. D. Willet, J. chem. Physics. 46, 401 [1967].

9 B. C. Gerstein, F. D. Gehring, and R. D. Willet, J. appl. Physies 43, 1932 [1972]. 